\title{
A Rectangular Micro Strip Patch Antenna for Ultra Wide Band Application Using HFSS Software
}

\author{
Ms. Laveena Mirchandani ${ }^{[1]}$, Ms. Lavina Solanki ${ }^{[2]}$, Mr. Abhishek Karwa ${ }^{[3]}$, \\ Mr. Ashish Mathur ${ }^{[4]}$ \\ ${ }^{[1]}$ B.TECH scholar, ECE, JIET School of Engg. and Technology for Girls Jodhpur, Rajasthan \\ ${ }^{[2]}$ B.TECH scholar, ECE, JIET School of Engg. and Technology for Girls Jodhpur, Rajasthan. \\ ${ }^{[3]}$ Asst. Professor, Dept. of ECE, JIET School of Engg. and Technology for Girls Jodhpur, Rajasthan, India. \\ ${ }^{[4]}$.Asso. Professor, Dept. of ECE, JIET School of Eng. and Technology for Girls Jodhpur, Rajasthan, India
}

\begin{abstract}
In this paper, the radiation performance of a compact micro strip patch antenna designed on glass epoxy FR4 substrate discussed. The proposed antenna is capable to cover Wi MAX, Wi Fi, WBAN and Bluetooth operations and UWB applications. The Simulated results for various parameters like radiation patterns, total field gain, return loss, VSWR, radiation efficiency etc. are also calculated with high frequency structure simulator HFSS. Its simulate results display impedance bandwidth from $3.10 \mathrm{GHz}$ to $10.06 \mathrm{GHz}$ the antenna complies with the return loss of S11 less then -1Odb and VSWR $<2$ throughout the impedance bandwidth.
\end{abstract}

Keywords: Ultra-Wide Band, Multiband Band, Patch antenna design, simulation, compact shape, patch, antenna, multiband, wireless, applications, using, hfss-11.

\section{Introduction}

Micro strip patch antennas are more popularly used now a day due to its various advantages such as light weight, less volume, compatibility with integrated circuits, easy to install on the rigid surface and low cost. Microstrip patch antennas are design to operate in dual-band and multi-band application either dual or circular polarization. These antennas are used in different handheld communicating devices [1]

Federal Communication Commission (FCC) permitted the authorization of using the unlicensed frequency band starting from 3.1 to $10.6 \mathrm{GHz}$ for commercial communication applications [2]. FCC (Federal communications commission) allocated a block of radio spectrum from $3.1 \mathrm{GHz}$ to $10.6 \mathrm{GHz}$ for UWB operations. UWB systems can support more than $500 \mathrm{Mbps}$ data transmission within $10 \mathrm{~m}$. Compact size, lowcost printed antennas with Wideband and Ultra wideband characteristic are desired in modern communications. The Ultra wide band antennas can be classified as directional and Omni-directional antennas [4]. A directional antenna has the high gain and relatively large in size. It has narrow field of view. Whereas the omni-directional antenna has low gain and relatively small in size. It has wide field of view as they radiate in all the directions [5]. The UWB antennas have broad band. There are many challenges in UWB antenna design. One of the challenges is to achieve wide impedance bandwidth. UWB antennas are typically required to attain a bandwidth, which reaches greater than $100 \%$ of the centre frequency to ensure a sufficient impedance match is attained throughout the band such that a power loss less than $10 \%$ due to reflections occurs at the antenna terminals[6].

\section{Literature Review}

According to [8] the substrate material plays significant role determining the size and bandwidth of an antenna. Increasing the dielectric constant decreases the size but lowers the bandwidth and efficiency of the antenna while decreasing the dielectric constant increases the bandwidth but with an increase in size. In [9] Microstrip patch antenna for GSM and Wi-Max application was proposed. The proposed antenna shows promising characteristics for WLAN, Wi-Max, and Satellite application at resonant frequencies of $5.5 \mathrm{GHz}$ for WiMax, $5.2 \mathrm{GHz}$ and $5.8 \mathrm{GHz}$ for WLAN and $6-7 \mathrm{GHz}$ for satellite application respectively. In [10]An Optimization of Circularly Polarized Knight's Helm Shaped Patch Antenna for Ultra Wide Band Application is designed, the radiation performance of a small printed knight's helm is capable to cover Wi MAX, Wi Fi, WBAN and Bluetooth operations and UWB applications. The Simulated results for various parameters like radiation patterns, total field gain, return loss, VSWR, radiation efficiency etc. are also calculated with high frequency structure simulator HFSS. Its simulate results display impedance bandwidth from $3.04 \mathrm{GHz}$ to $10.96 \mathrm{GHz}$ the antenna complies with the return loss of S11 less then -10db and VSWR $<2$ throughout the impedance bandwidth. 


\section{Antenna Configuration And Design}

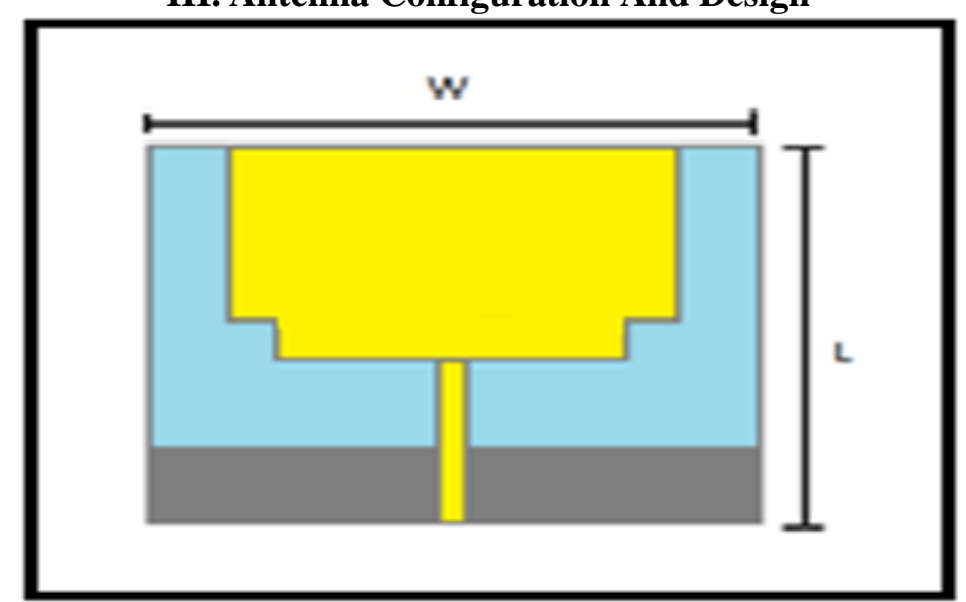

FIG 1. Design of Patch Antenna

For designing of a Microstrip patch antenna, we have to select the resonant frequency and a dielectric medium for which antenna is to be designed [11].

The parameters to be calculated are as under:

The width of the patch is calculated using the following equation:

$$
W=\frac{C_{0}}{2 f_{r}} \sqrt{\frac{2}{\varepsilon_{r}+1}}
$$

Where

$W=$ Width of the patch, $=$ Speed of light,$\varepsilon_{\mathrm{r}}=$ value of the dielectric substrate

Effective refractive index: The effective refractive index value of a patch is an important parameter in the designing procedure of a microstrip patch antenna. The radiations traveling from the patch towards the ground pass through air and some through the substrate (called as fringing). Bath the air and the substrates have different dielectric values, therefore in order to account this we find the value of effective dielectric constant. The value of the effective dielectric constant $(\varepsilon)$ is calculated using the following equation:

$$
\varepsilon_{\text {reff }}=\frac{\varepsilon_{r}+1}{2}+\frac{\varepsilon_{r}-1}{2}\left[1+12 \frac{h}{W}\right]^{-1 / 2}, W / h>1
$$

Due to fringing, electrically the size of the antenna is increased by an amount of $(\Delta \mathrm{L})$. Therefore, the actual increase in length $(\Delta \mathrm{L})$ of the patch is to be calculated using the following equation:

$$
\frac{\Delta L}{h}=0.412 \frac{\left(\varepsilon_{\text {reff }}+0.3\right)\left(\frac{W}{h}+0.264\right)}{\left(\varepsilon_{\text {reff }}-0.258\right)\left(\frac{W}{h}+0.8\right)}
$$

Where ' $h$ ' $=$ height of the substrate the length $(\mathrm{L})$ of the patch is now to be calculated using the below mentioned equation:

$$
L=\frac{C_{0}}{2 f_{r} \sqrt{\varepsilon_{r e f f}}}-2 \Delta L
$$

Length $(\mathrm{Lg})$ and width $(\mathrm{Wg})$ of ground plane: Now the dimensions of a patch are known. The length and width of a substrate is equal to that of the ground plane. The length of a ground plane $(\mathrm{Lg})$ and the width of a ground plane $(\mathrm{Wg})$ are calculated using the following equations:

$$
\begin{gathered}
L_{g}=6 h+L \\
W_{g}=6 h+W
\end{gathered}
$$

For feeding the micro strip patch antenna, there are different methods for example, feed line method, coaxial probe feeding method etc. But mostly coaxial probe method is used. 


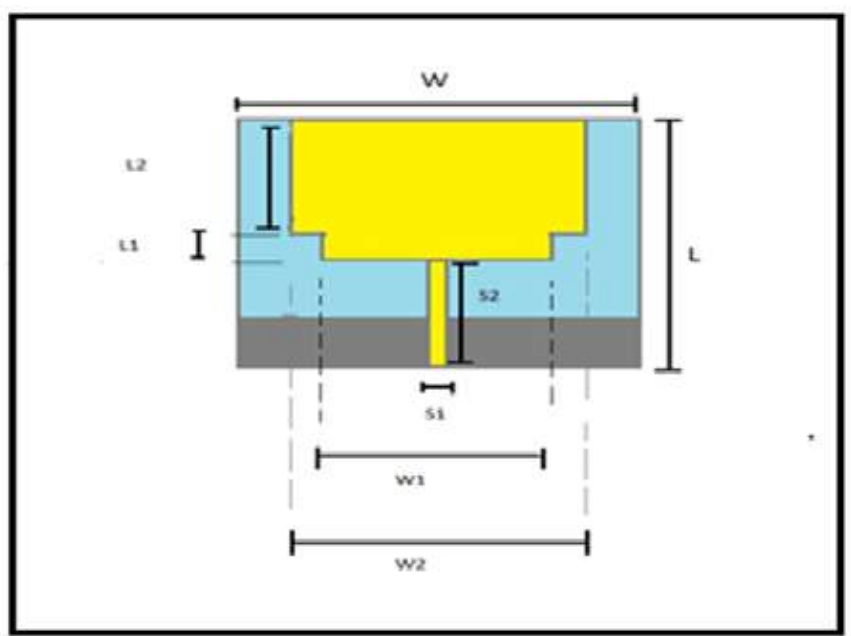

Fig 2. Dimensions of Patch Antenna

Table 1 Designing Parameter of Antenna

\begin{tabular}{|l|l|l|l|l|l|l|l|l|l|}
\hline $\mathbf{W}$ & $\mathbf{L}$ & $\mathbf{W 1}$ & $\mathbf{L 1}$ & $\mathbf{W 2}$ & $\mathbf{L 2}$ & $\mathbf{S 1}$ & $\mathbf{S 2}$ & $\mathbf{L G}$ & WG \\
\hline $30 \mathrm{~mm}$ & $30 \mathrm{~mm}$ & $14 \mathrm{~mm}$ & $3 \mathrm{~mm}$ & $20 \mathrm{~mm}$ & $14 \mathrm{~mm}$ & $1.45 \mathrm{~mm}$ & $12 \mathrm{~mm}$ & $11 \mathrm{~mm}$ & $30 \mathrm{~mm}$ \\
\hline
\end{tabular}

$\mathbf{W}=$ width of substrate, $\mathbf{L}=$ length of substrate, $\mathbf{W} \mathbf{1}=$ width of patch $1, \mathbf{L} \mathbf{1}=$ length of patch $1 \mathbf{W} \mathbf{2}=$ =width of patch $2, \mathbf{L} 2=$ length of patch 2, $\mathbf{S 1}=$ width of microstrip, $\mathbf{S 2}=$ length of microstrip , $\mathbf{L} \mathbf{G}=$ length of ground, $\mathbf{W G}=$ width of ground

\section{Proposed Design Of Patch Antenna}



Fig 3. The Proposed Design of Patch in HFSS

\section{Simulation Results}

This antenna is suitable for operating frequency $3.10 \mathrm{GHz}$ to $10.06 \mathrm{GHz}$ allotted by working group for UWB applications. The VSWR obtained is less than 2 the patch antenna is found to have the compact size and $90 \%$ Maximum Fractional Bandwidth. The return loss value of band is $-25.72 \mathrm{~dB}$ at $4.9 \mathrm{GHz}$.

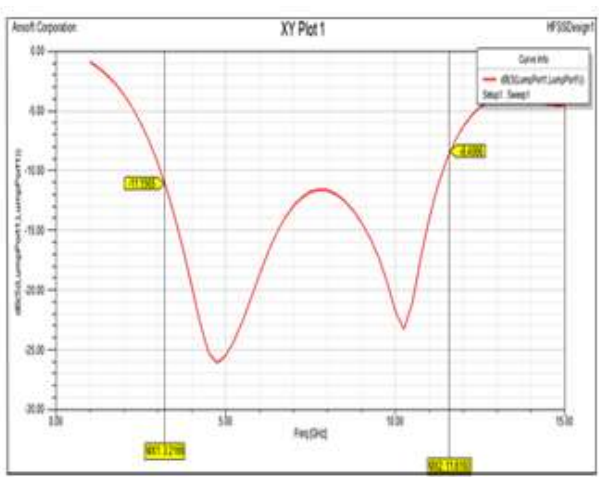

Fig 4. S11 Parameter Vs Freq Plot

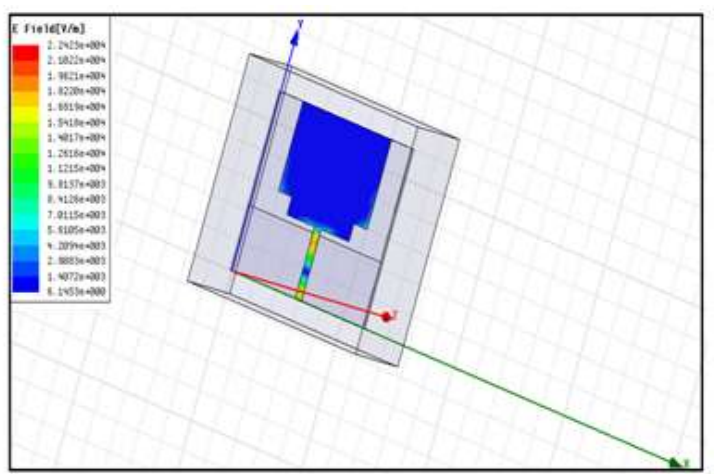

Fig 5. E Field Pattern 


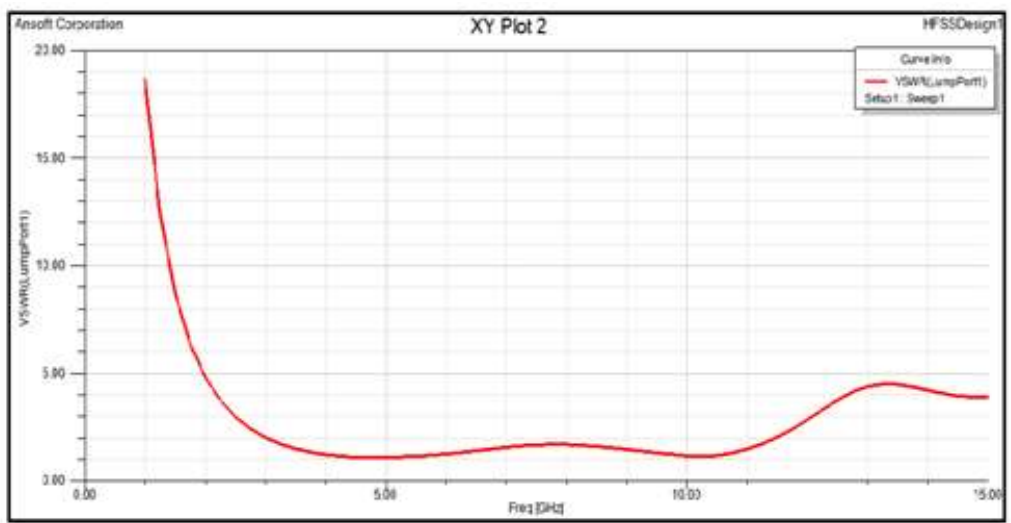

Fig 6. VSWR Measurements

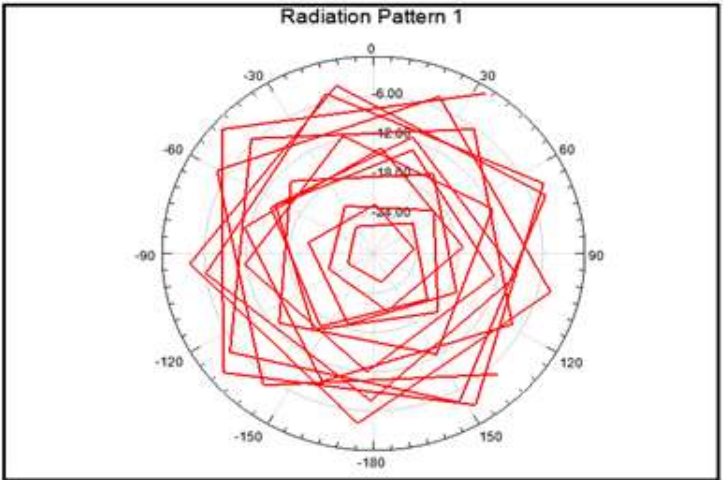

Fig 7. Radiation Pattern

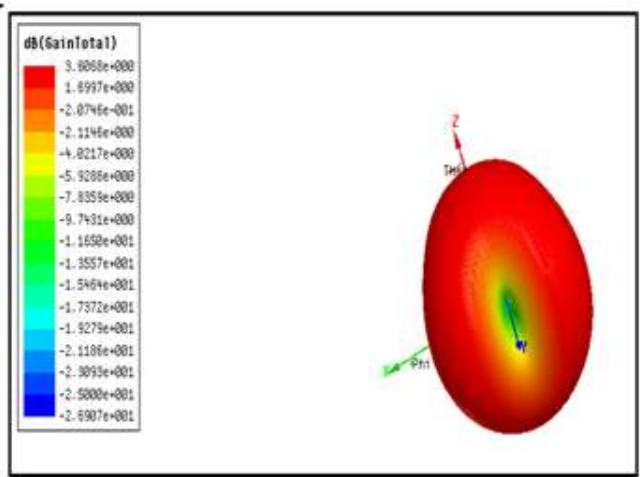

Fig 8. 3d Polar Plot

\section{Conclusion}

The fabricated antenna has advantages of small size, easy fabrication and simple construction. Antenna is compact shaped and operates at $3.10 \mathrm{GHZ}$ to $10.06 \mathrm{GHz}$ with Absolute Bandwidth 8.301MHz. Radiation performance of patch antenna is also presented in this paper. The simulated results indicate that an ultrawide band antenna with Maximum Fractional Bandwidth 8.301MHZ can be achieved we conclude that proposed geometry is applicable for ultrawide band from $3.1 \mathrm{GHz}$ to $10.6 \mathrm{GHz}$ In future the Radiation performance of novel Shape rectangular patch antenna can be improved by using different feeding techniques.

\section{References}

[1]. Rajeshwar Lal Dua, Himanshu Singh, "2.45 GHz Microstrip Patch Antenna with Defected Ground Structure for Bluetooth", IJSCE, ISSN: 2231-2307, Volume-1, January 2012

[2]. FCC report and order for part-15 acceptance of ultra wide band systems (UWB) from 3.1 to $10.6 \mathrm{GHz}$, washington, DC,2002

[3]. Ashish Mathur ,Deepak Sharma, Geetika Mathur "Design and Simulation of Dual Band Patch Antenna for Ultra Wide Band (UWB) Applications Using HFSS, ICMARS2012- Jodhpur, Volume 1, Issue 1 pp.771-774, December 11-15, 2012.

[4]. Ashish Mathur,Deepak Sharma, Geetika Mathur "Design and Simulation of Rectangular and Half Ring Patch Antenna for Ultra Wide Band (UWB) Applications Using HFSS, ICMARS2012- Jodhpur, Volume 1, Issue 1 pp.296-300, December 11-15, 2012.

[5]. Ashish Mathur ,Deepak Sharma, GeetikaMathur "Design and Simulation of Dual Band Patch Antenna for ISM, WI-MAX and CBand Rejection Using HFSS" in International Conference in Advancement on Information Technology (ICAIT), Souvenir March 22-23, 2013.

[6]. P.S. Ashtankar and C.G.Dethe "Design and Modification of Circular Monopole UWB Antenna for WPAN Application Computer Engineering and Intelligent Systems ISSN 2222-1719 (Paper) ISSN 2222-2863 (Online) Vol 3, No.5, 2012.

[7]. Ashish mathur, Geetika Mathur, Harsh Dutt Mathur "To Enhance the Bandwidth of Small Printed Inverted T- Shaped Patch Antenna for Wireless and WBAN Applications".

[8]. Ashish Kumar, Bimal Garg, "Rectangular Microstrip Patch Antenna Loaded With Double Orthogonal Crossed Slits In Ground Plane “, International Journal of Advance Technology \& Engineering Research.2011.

[9]. Neha Ahuja , Rajesh Khanna, Jaswinder kaur, "Dual Band Defected Ground Microstrip Patch Antenna for WLAN / WiMaxand Satellite Application “, International Journal of Computer Applications, Volume 48- No.22, June 2011.

[10]. Mr. Abhishek Karwa, Mr. Ashish Mathur , Mrs. Geetika Mathur "An Optimization Of Circularly Polarized Knight’s Helm Shaped Patch Antenna For Ultra Wide Band Application".

[11]. Muhammad Aamir Afridi( MS Telecommunication Engineering, University of Engineering and Technology (UET) Peshawar, Mardan Campus, Pakistan) "Microstrip Patch Antenna - Designing at $2.4 \mathrm{GHz}$ Frequency".

[12]. HFSSv10 user guide.pdf 